\title{
The relationship of socio-demographic and reproductive factors with preferred type of birth
}

\section{Zahra Abbaspoor, Mojgan Javad Noori*}

\begin{abstract}
Department of Reproductive Health Improvement Research Centre, Ahvaz Jundishapur University of Medical
\end{abstract} Sciences, Ahvaz, Iran

Received: 15 April 2016

Accepted: 09 May 2016

\section{*Correspondence:}

Dr. Mojgan Javad Noori,

E-mail: mj52noori@yahoo.com

Copyright: (C) the author(s), publisher and licensee Medip Academy. This is an open-access article distributed under the terms of the Creative Commons Attribution Non-Commercial License, which permits unrestricted non-commercial use, distribution, and reproduction in any medium, provided the original work is properly cited.

\begin{abstract}
Background: Caesarean section is increasingly prevalent and in most developing countries it rates over 50 percent. This study aimed to examine the relationship between, socio-demographic, economic and reproductive factors with birth method selection.

Methods: In this cross-sectional study 510 pregnant women or women had undergone an elective caesarean section in the absence of any medical indication were selected from individuals referring to health centers or postpartum wards of hospitals in Ahvaz, Iran, from February 2015 to June 2015. A questionnaire consisted of 26 questions, was used to collect data. The validity and reliability of the questionnaire was confirmed. In order to analyze the data statistical software SPSS 22 was used to perform chi-square and independent t-tests.

Results: The findings revealed the mean age of mothers was $26.97 \pm 4.5$ years and the majority of them (14.3\%) had a diploma level. They were mostly housewives (87.3\%). There was a significant difference between two groups regarding socio- demographic and economic characteristics $(p<0.000)$, but reproductive factors such as parity, trimester of pregnancy, history of infertility, abortion, fetal abnormality, neonatal death, IUFD, unwanted pregnancy and baby sex were not related to this selection. Midwife and prenatal classes were the main sources of their acquired information $(\mathrm{p}<0.000)$.

Conclusions: Socio-demographic and economic characteristics are contribute to birth method selection and midwives and prenatal classes are the main resource for giving information about the advantages of vaginal delivery and disadvantages of Cesarean section. Well-designed Studies in this area is very few and further studies are recommended.
\end{abstract}

Keywords: Cesarean section, Vaginal delivery, Socio-demographic, Economic

\section{INTRODUCTION}

Childbearing is a natural process and occurs without medication or obstetric intervention. Vaginal delivery may need to any number of medical interventions such as cesarean section. ${ }^{1}$ As early as 1980 , the national cesarean section rate hovered around $15 \%$, but the rates of this procedure have risen dramatically during the past decade, reaching more than $50 \%$ in some countries. ${ }^{2,3}$ Reported that in 2007 in U.S. (2007) nearly 32\% (1.4 millions) of all births have been the result of caesarean deliveries 4 .In
Iran, the increasing rate of caesarean deliveries is higher than the $(10-15 \%)$ recommended rate by WHO.-7 In capital city, Tehran, in 2002, the total rate of caesarean section was reported to be $66.5 \%$, rising to as high as $84 \%$ in private centers. ${ }^{8}$ In Ahvaz, another large city of Iran, the rate of caesarean deliveries in 2010 was $41.3 \%$ in teaching hospitals. ${ }^{9}$

Caesarean deliveries increase the risk of maternal and neonatal mortality and morbidity, compared to vaginal delivery. ${ }^{3}$ Several studies have assessed the possible 
reasons for the increasing caesarean delivery rates and some of them reported that maternal request is a significant factor in the rising caesarean section rates. ${ }^{10}$ Some known factors associated to preferring a cesarean section without medical indication by women, is maternal age over 35 years, a previous negative birth, childbirth fear, perceptions about safety of mother and baby, previous negative birth experiences, poor care and perceived inequalities in care. ${ }^{11,12}$

Also the relationship between socio-economic factors such as smoking, unemployment and ethnic background has proven. ${ }^{11,13-15}$ Also it has been reported that women planning a cesarean section differ to some extent in their personality from women to choose a vaginal delivery. ${ }^{11}$ Types of information provided by health professionals and information assessed through public and private discourses of family, friends and acquaintances have reported as influencing factors on women's preferred type of delivery. ${ }^{16,17}$

However, many women prefer to do vaginal birth. ${ }^{16}$ Fenwick et al in their study identified that women who preferred a vaginal birth after Caesarean (VBAC) believed that birth was a significant and important event. Also attitudes of family, friends and the woman's reflections of the previous caesarean experience influenced the women choice to have a VBAC 18 . Although reasons for women's birth selection have investigated in many studies, few studies have examined characteristics of women who prefer normal vaginal deliver or cesarean section. Understanding of women characteristics and factors contributing to the increasing rate of caesarean delivery is important to planning and implementation of safe and successful strategies to reduce unnecessary interventions in child birthing process. ${ }^{19}$ This cross-sectional study aims to examine the relationship between, socio-demographic, economic and reproductive factors with birth method selection in Iranian women.

\section{METHODS}

In this cross-sectional study that carried in Ahvaz-Iran, 510 women who were chosen their birth methods and were referred to two educational hospitals (Imam Khomeini and Razi (and two health centers from February 2015 to June 2015, were participated. The study was approved by the ethics committee of Ahvaz Jundishapur University of Medical Sciences, and written informed consent was obtained from all participants. The inclusion criteria were included: women who could read and wright in Persian, had a normal singleton with an expected normal obstetric outcome. Women who had a medical reason for cesarean section were excluded from study. All participants signed an informed consent prior to the study and completed a socio-demographic, economic and reproductive status questionnaire and types of information gathered through interview.

\section{Statistical analysis}

Data were analyzed using SPSS 22.0. The descriptive statistics were utilized to describe the groups. The differences between the characteristics of women in cesarean section and normal vaginal delivery groups were compared using independent t-test and chi-square. The pvalue less than 0.05 considered as significant.

\section{RESULTS}

The mean age was 26.07 and 27.9 in the vaginal delivery and cesarean section groups, respectively. In vaginal delivery $2.7 \%$ and in cesarean section group $10.5 \%$ were employed. There was a significant difference between two groups regarding socio-demographic and economic characteristics. Two groups did not have any statistical difference regarding field of study (medical or nonmedical) $(\mathrm{p}>0.05)$ (Table 1).

Table 1: Demographic and socio-economic characteristics of women in the normal delivery and cesarean Section groups $(\mathbf{n}=\mathbf{5 1 0})$.

\begin{tabular}{|c|c|c|c|c|}
\hline \multirow[b]{2}{*}{ Characteristic } & \multicolumn{3}{|c|}{ Chosen birth method } & \multirow[b]{2}{*}{ P Value } \\
\hline & ND & CS & Total & \\
\hline & $(n=264)$ & $(\mathrm{n}=246)$ & $(\mathrm{n}=\mathbf{5 1 0})$ & \\
\hline Age, y, mean (SD) & $26.07(4.5)$ & $27.93(5.3)$ & $26.97(5.02)$ & 0.000 \\
\hline Marriage age, y, mean (SD) & $21.06(4)$ & $22.56(4.46)$ & $21.78(4.30)$ & 0.000 \\
\hline \multicolumn{4}{|l|}{ Place of Residency, n (\%) } & \multirow[t]{3}{*}{0.000} \\
\hline Urban & $224(43.9 \%)$ & $239(46.9 \%)$ & $463(90.8 \%)$ & \\
\hline Rular & $40(7.8 \%)$ & $7(1.4 \%)$ & $47(9.2 \%)$ & \\
\hline \multicolumn{4}{|l|}{ Ethnicity, n (\%) } & \multirow{6}{*}{0.000} \\
\hline persian & $85(16.7 \%)$ & $121(23.7 \%)$ & $206(40.4 \%)$ & \\
\hline Arab & $148(29 \%)$ & $75(14.7 \%)$ & $223(43.7 \%)$ & \\
\hline Lor & $20(3.9 \%)$ & $42(8.2 \%)$ & $62(12.2 \%)$ & \\
\hline Kurdish & $9(1.8 \%)$ & $3(0.6 \%)$ & $12(2.4 \%)$ & \\
\hline Turkish & $2(.6 \%)$ & $5(1 \%)$ & $7(1.4 \%)$ & \\
\hline
\end{tabular}




\begin{tabular}{|c|c|c|c|c|}
\hline \multicolumn{4}{|l|}{ Educational level, No. (\%) } & \multirow[t]{6}{*}{0.000} \\
\hline Primary school & $48(9.4)$ & $14(2.8)$ & $62(12.2 \%)$ & \\
\hline Secondary & $37(7.3)$ & $16(3.1 \%)$ & $53(10.4 \%)$ & \\
\hline High school & $35(6.9)$ & $22(4.3 \%)$ & $57(11.2 \%)$ & \\
\hline Diploma & $73(14.3)$ & $97(19.0 \%)$ & $170(33.3 \%)$ & \\
\hline University & $71(13.9)$ & $87(19.0 \%)$ & $168(32.9 \%)$ & \\
\hline \multicolumn{4}{|l|}{ Husband Educational level, No. (\%) } & \multirow[t]{6}{*}{0.000} \\
\hline Primary school & $36(7.1)$ & $12(2.4)$ & $48(9.4 \%)$ & \\
\hline Secondary & $47(9.2)$ & $16(3.1 \%)$ & $63(12.4 \%)$ & \\
\hline High school & $23(4.5)$ & $23(4.5)$ & $39(7.6 \%)$ & \\
\hline Diploma & $52(12.2)$ & $73(14.3 \%)$ & $125(24.5 \%)$ & \\
\hline University & $106(20.7)$ & $129(25.2 \%)$ & $235(45.9 \%)$ & \\
\hline \multicolumn{4}{|l|}{ Field of study, No. (\%) } & \multirow[t]{3}{*}{0.103} \\
\hline Medical & $4(0.8 \%)$ & $9(1.8 \%)$ & $13(2.6 \%)$ & \\
\hline Non-medical & $57(11.2 \%)$ & $76(14.9 \%)$ & $133(26.1 \%)$ & \\
\hline \multicolumn{4}{|l|}{ Occupation, women, No. (\%) } & \multirow[t]{3}{*}{0.000} \\
\hline Housewife & $248(48.6 \%)$ & $197(38.6 \%)$ & $445(87.3 \%)$ & \\
\hline Employee & $14(2.7 \%)$ & $49(10.5 \%)$ & $63(12.4 \%)$ & \\
\hline \multicolumn{4}{|l|}{ Occupation, men, No. (\%) } & \multirow[t]{5}{*}{0.002} \\
\hline Jobless & $10(2 \%)$ & $147(28.8 \%)$ & $12(2.4 \%)$ & \\
\hline Worker & $20(3.9 \%)$ & $20(3.9 \%)$ & $40(7.8 \%)$ & \\
\hline Employee & $87(17.1 \%)$ & $120(23.5 \%)$ & $207(40.6 \%)$ & \\
\hline Self-administered & $147(28.8 \%)$ & $104(20.4 \%)$ & $251(49.2 \%)$ & \\
\hline \multicolumn{4}{|l|}{ Housing Status, No. (\%) } & \multirow[t]{4}{*}{0.000} \\
\hline Owner of the house & $97(19.0 \%)$ & $113(22.2 \%)$ & $210(41.2 \%)$ & \\
\hline House rental & $74(14.5 \%)$ & $78(15.3 \%)$ & $152(29.8 \%)$ & \\
\hline Living with family & $93(18.3 \%)$ & $55(10.8 \%)$ & $148(29.0 \%)$ & \\
\hline \multicolumn{4}{|l|}{$\begin{array}{l}\text { Number of people in the family, No. } \\
(\%)\end{array}$} & \multirow[t]{3}{*}{0.001} \\
\hline $2-4$ & $166(32.6 \%)$ & $201(39.4 \%)$ & $367(71.9 \%)$ & \\
\hline$\geq 5$ & $98(19.4 \%)$ & $45(8.8 \%)$ & $143(27.6 \%)$ & \\
\hline \multicolumn{4}{|l|}{ Economic status, No. (\%) } & \multirow[t]{4}{*}{0.001} \\
\hline Good & $92(18.1 \%)$ & $68(13.7 \%)$ & $162(31.8 \%)$ & \\
\hline Moderate & $145(28.4 \%)$ & $170(33.3 \%)$ & $315(61.8 \%)$ & \\
\hline poor & $27(5.3 \%)$ & $6(1.2 \%)$ & $33(6.5 \%)$ & \\
\hline \multicolumn{4}{|l|}{ Insurance cover, No. (\%) } & \multirow[t]{3}{*}{0.000} \\
\hline No insurance & $35(7.9 \%)$ & $20(3.8 \%)$ & $55(11.7)$ & \\
\hline Health service insurance & $227(45 \%)$ & $226(44.3 \%)$ & $453(89.3 \%)$ & \\
\hline
\end{tabular}

Table 2: Reproductive characteristics of women in the normal delivery and cesarean section groups $(\mathrm{n}=\mathbf{5 1 0})$.

\begin{tabular}{|c|c|c|c|c|}
\hline \multicolumn{5}{|c|}{ Chosen birth method } \\
\hline Characteristic & ND & CS & Total & P Value \\
\hline & $(n=264)$ & $(n=246)$ & $(n=510)$ & \\
\hline Gravidity, N (\%) & & & & 0.049 \\
\hline Primi gravida & $133(26.1 \%)$ & $134(26.3 \%)$ & $267(52.4 \%)$ & \\
\hline $2-4$ & $244(25 \%)$ & $106(20.8 \%)$ & $234(45.9 \%)$ & \\
\hline$\geq 5$ & $3(0.6 \%)$ & $6(1.2 \%)$ & $9(1.8 \%)$ & \\
\hline Parity, N (\%) & & & & 0.460 \\
\hline Nulliparous & $143(28.0 \%)$ & $143(28.0 \%)$ & $286(56.1 \%)$ & \\
\hline $1-3$ & $139(24.4 \%)$ & $79(19.4 \%)$ & $218(48.2 \%)$ & \\
\hline$\geq 4$ & $2(0.4 \%)$ & $4(0.6 \%)$ & $6(1 \%)$ & \\
\hline Pregnancy trimester, N (\%) & & & & 0.650 \\
\hline First & $4(0.8 \%)$ & $4(0.8 \%)$ & $8(1.6 \%)$ & \\
\hline Second & $24(4.8 \%)$ & $16(3.2 \%)$ & $40(7.9 \%)$ & \\
\hline Third & $236(46.3 \%)$ & $226(44.3 \%)$ & $462(90.6 \%)$ & \\
\hline
\end{tabular}




\begin{tabular}{|c|c|c|c|c|}
\hline \multicolumn{5}{|l|}{ Previous infertility, N (\%) } \\
\hline Yes & $0(0.0 \%)$ & $4(0.8 \%)$ & $4(0.8 \%)$ & \multirow[t]{2}{*}{0.087} \\
\hline No & $264(51.8 \%)$ & $242(47.5 \%)$ & $506(99.3 \%)$ & \\
\hline \multicolumn{4}{|l|}{ Previous Abortion, N (\%) } & \multirow[t]{4}{*}{0.864} \\
\hline 0 & $231(45.3 \%)$ & $215(42.2 \%)$ & $446(87.5 \%)$ & \\
\hline 1 & $31(6.1 \%)$ & $28(5.5 \%)$ & $59(11.6 \%)$ & \\
\hline 2 & $2(0.4 \%)$ & $3(0.6 \%)$ & $5(1.0 \%)$ & \\
\hline \multicolumn{4}{|c|}{ Previous fetal abnormality, N (\%) } & \multirow[t]{3}{*}{0.503} \\
\hline Yes & $2(0.5 \%)$ & $2(0.4 \%)$ & $4(0.9 \%)$ & \\
\hline No & $226(53.8)$ & $190(45.2 \%)$ & $416(99.0 \%)$ & \\
\hline \multicolumn{4}{|l|}{ Child death number, N (\%) } & \multirow[t]{3}{*}{0.301} \\
\hline Yes & $1(0.2 \%)$ & $3(0.7 \%)$ & $4(1.0 \%)$ & \\
\hline No & $227(54.0)$ & $189(45.0 \%)$ & $416(99.0 \%)$ & \\
\hline \multicolumn{4}{|l|}{ IUFD number, $\mathbf{N}(\%)$} & \multirow[t]{3}{*}{0.179} \\
\hline Yes & $3(0.7 \%)$ & $2(0.4 \%)$ & $5(1.1 \%)$ & \\
\hline No & $225(53.6)$ & $190(45.2 \%)$ & $415(98.8 \%)$ & \\
\hline \multicolumn{4}{|c|}{ Unwanted pregnancy number, $\mathbf{N}(\%)$} & \multirow[t]{3}{*}{0.543} \\
\hline Yes & $2(0.5 \%)$ & $3(0.7 \%)$ & $5(1.2 \%)$ & \\
\hline No & $226(53.8)$ & $189(45.0 \%)$ & $415(98.8 \%)$ & \\
\hline \multicolumn{4}{|l|}{ Previous birth method, N (\%) } & \multirow[t]{3}{*}{0.000} \\
\hline ND & $109(26.0 \%)$ & $31(7.4 \%)$ & $140(33.3 \%)$ & \\
\hline $\mathrm{CS}$ & $3(0.7)$ & $44(10.5 \%)$ & $47(11.2 \%)$ & \\
\hline \multicolumn{4}{|c|}{ Previous birth method satisfaction, N (\%) } & \multirow[t]{3}{*}{0.001} \\
\hline Yes & $98(23.3 \%)$ & $52(12.4 \%)$ & $150(35.7 \%)$ & \\
\hline No & $12(2.9)$ & $23(5.5 \%)$ & $35(8.3 \%)$ & \\
\hline \multicolumn{4}{|l|}{ Delivery agent, $\mathrm{N}(\%)$} & \multirow[t]{4}{*}{0.000} \\
\hline Midwife & $92(21.9 \%)$ & $26(6.2 \%)$ & $118(26.1 \%)$ & \\
\hline Obstetrician & $16(3.8 \%)$ & $48(11.4 \%)$ & $64(15.2 \%)$ & \\
\hline Others & $3(0.6 \%)$ & $0(0.0 \%)$ & $3(0.6 \%)$ & \\
\hline \multicolumn{4}{|c|}{ Breast feeding first time in previous birth, $N(\%)$} & \multirow[t]{3}{*}{0.000} \\
\hline First 1 hour & $92(21.9 \%)$ & $45(10.7 \%)$ & $137(32.6 \%)$ & \\
\hline After 1 hour & $19(4.5)$ & $29(6.9 \%)$ & $48(11.4 \%)$ & \\
\hline Gestational age, w, mean (SD) & $27.77(2.34)$ & $27.95(2.12)$ & $27.86(2.23)$ & 0.728 \\
\hline Pregnancy times, $n$, mean (SD) & $1.7(0.79)$ & $1.7(0.96)$ & $1.7(0.87)$ & 1.000 \\
\hline \multicolumn{4}{|l|}{ Baby Sex, N (\%) } & \multirow[t]{3}{*}{0.405} \\
\hline Boy & $105(39.77)$ & $91(36.99)$ & $196(38.43)$ & \\
\hline Girl & $88(33.33)$ & $80(32.52)$ & $168(32.94)$ & \\
\hline
\end{tabular}

Table 3: Sources of information of women in the normal delivery and cesarean section groups $(\mathbf{n}=\mathbf{5 1 0})$.

\begin{tabular}{|c|c|c|c|c|}
\hline \multirow{3}{*}{ Sources of information, } & \multicolumn{4}{|c|}{ Chosen birth method } \\
\hline & ND & CS & Total & P Value \\
\hline & $(n=264) N(\%)$ & $(n=246) N(\%)$ & $(n=510)$ & \\
\hline \multicolumn{4}{|l|}{ Physician } & \multirow{3}{*}{0.106} \\
\hline Yes & $39(46.4 \%)$ & $45(53.6 \%)$ & $84(100 \%)$ & \\
\hline No & $189(56.3 \%)$ & $147(43.8 \%)$ & $336(100 \%)$ & \\
\hline \multicolumn{4}{|l|}{ Midwife } & \multirow{3}{*}{0.000} \\
\hline Yes & $107(87.7 \%)$ & $15(12.3 \%)$ & $122(100 \%)$ & \\
\hline No & $121(40.6 \%)$ & $177(59.4 \%)$ & $298(100 \%)$ & \\
\hline \multicolumn{4}{|l|}{ Perinatal classes } & \multirow{3}{*}{0.000} \\
\hline Yes & $25(96.2 \%)$ & $1(3.8 \%)$ & $26(100 \%)$ & \\
\hline No & $203(51.5 \%)$ & $191(48.2 \%)$ & $394(100 \%)$ & \\
\hline \multicolumn{4}{|l|}{ Internet } & \multirow{3}{*}{0.537} \\
\hline Yes & $23(59.0 \%)$ & $16(41 \%)$ & $39(100 \%)$ & \\
\hline No & $205(53.8 \%)$ & $176(46.2 \%)$ & $381(100 \%)$ & \\
\hline
\end{tabular}




\begin{tabular}{|c|c|c|c|c|}
\hline \multicolumn{4}{|c|}{ Book } & \multirow{3}{*}{0.237} \\
\hline Yes & $27(62.8 \%)$ & $16(37.2 \%)$ & $43(100 \%)$ & \\
\hline No & $201(53.3 \%)$ & $176(46.7 \%)$ & $377(100 \%)$ & \\
\hline \multicolumn{4}{|c|}{ Newspaper } & \multirow{3}{*}{0.096} \\
\hline Yes & $10(76.9 \%)$ & $3(23.1 \%)$ & $13(100 \%)$ & \\
\hline No & $218(53.6 \%)$ & $189(45.8 \%)$ & $407(100 \%)$ & \\
\hline \multicolumn{4}{|c|}{ University Class } & \multirow{3}{*}{0.878} \\
\hline Yes & $4(57.1 \%)$ & $3(42.9 \%)$ & $7(100 \%)$ & \\
\hline No & $224(54.2 \%)$ & $189(45.8 \%)$ & $413(100 \%)$ & \\
\hline \multicolumn{4}{|c|}{ Advertisement } & \multirow{3}{*}{0.403} \\
\hline Yes & $3(75 \%)$ & $1(25 \%)$ & $4(100 \%)$ & \\
\hline No & $225(54.1 \%)$ & $191(45.9 \%)$ & $415(100 \%)$ & \\
\hline \multicolumn{4}{|c|}{ Pamphlet } & \multirow{3}{*}{0.796} \\
\hline Yes & $3(60.0 \%)$ & $2(40.0 \%)$ & $5(100 \%)$ & \\
\hline No & $225(54.2 \%)$ & $190(45.8 \%)$ & $415(100 \%)$ & \\
\hline \multicolumn{4}{|c|}{ Family } & \multirow{3}{*}{0.001} \\
\hline Yes & $130(62.8 \%)$ & $77(37.2 \%)$ & $207(100 \%)$ & \\
\hline No & $98(46.0 \%)$ & $115(54.0 \%)$ & $213(100 \%)$ & \\
\hline \multicolumn{4}{|c|}{ Relatives } & \multirow{3}{*}{0.348} \\
\hline Yes & $100(51.8 \%)$ & $93(48.2 \%)$ & $193(100 \%)$ & \\
\hline No & $128(56.4 \%)$ & $99(43.6 \%)$ & $227(100 \%)$ & \\
\hline \multicolumn{4}{|c|}{ Previous childbirth experience } & \multirow{3}{*}{0.472} \\
\hline Yes & $93(52.2 \%)$ & $85(47.8 \%)$ & $178(100 \%)$ & \\
\hline No & $135(55.8 \%)$ & $107(44.2 \%)$ & $242(100 \%)$ & \\
\hline
\end{tabular}

According to the Independent t- test there was not any significant difference between two groups regarding gestational age and gravidity $(p>0.05)$. Chi square test showed a significant differences between two groups regards to previous birth method, previous birth method satisfaction, delivery agent and early starting breast feeding in previous birth $\mathrm{p}<0.000$ ). But, there was no difference between two groups regards to parity, trimester of pregnancy, history of infertility, abortion, fetal abnormality, neonatal death, IUFD, unwanted pregnancy and baby sex (Table 2). Table 3 is presenting results of chi-square test for sources of information that women received for their birth method selection. There was a significant difference between two groups regards to midwife and prenatal classes as the main source of their required information $(\mathrm{p}<0.000)$. There was not any significant relationship between groups about the other sources of information (Table 3).

\section{DISCUSSION}

In this study we examined the relationship of, sociodemographic, economic and reproductive characteristics with birth method selection in Iranian women. All women were chosen their birth method in absent of any medical indication. We excluded any high risk pregnancy. The age and marriage age of women in caesarean section group were significantly higher than normal delivery. In a study researcher found that maternal age over 35 years is a factor contributing to demand for caesarean section. ${ }^{11}$ Also in a study in
Southern Italy researchers showed that a high number of women who wished to give birth by caesarean section, were aged $\geq 35$ years with a high level of education, previous infertility, history of smoking, sufficient information provided, and desire for more knowledge. ${ }^{20}$ Also, in Sweden, women requesting a caesarean section were older but had a lower social class. ${ }^{11}$ WHO study in Latine America, found that women who were single, young and less educated were more likely to deliver vaginally. ${ }^{21}$ In present study economic factors include, place of living, employment status of women and men, hosing status, economic status in participant opinion, and insurance status were significantly different in vaginal delivery and caesarean section groups and women who planned or performed a caesarean section were, more lived in urban, more employed and their husbands were more employed, more hosing owner, more having insurance and had a moderate economic status. Vafaee et al in their study on 417 women (212 caesarean section and 205 vaginal deliveries) showed that $67.4 \%$ of women who preferred caesarean section were resident in urban and compared to vaginal delivery this difference was significant. ${ }^{22}$ But in other study birth method selection was not related to family income and mother employment. ${ }^{23}$ Also, maternal health insurance and hospital admission status were reported as factors to contribute to rising caesarean section rate in developed countries. ${ }^{24-26}$ In Murray study also women with health insurance cover and private obstetrician, requested higher rates of caesarean section. ${ }^{27}$ One study reported that caesarean delivery is a conventional economic good, in 
the sense that the higher one's income the more one is inclined to "purchase" it and it shows that primarily women's choices determine caesarean section rates. ${ }^{28}$ In caesarean section group than the vaginal delivery the most women and their husbands were educated in diploma and university level. But there was not any significant difference between two groups regarding Field of study and studying in medical field not differ from non-medical field.

In a study conducted by WHO, women who delivered by caesarean section without any medical indication were more likely educated (more than 12 years of formal education). ${ }^{29}$ Also, Nourizadeh showed that with increasing the educational level, tendency to doing caesarean section was increased. ${ }^{23}$ Researchers have found that some Brazilian women consider caesarean section to be a high-class mode of birth. ${ }^{30}$ Also, in agreement with our previous study, Iranian women also consider caesarean section as a high-class mode of delivery. ${ }^{31}$ But, Swedish women believed that requesting a caesarean section have a lower social class than vaginal delivery. ${ }^{11}$

In present study there was not any significant difference between two groups regards to gravidity, parity, history of infertility, fetal abnormality, neonatal death, IUFD, unwanted pregnancy, gestational age and baby sex. In A study has done by Nourizadeh, also there was no significant difference between gravidity, parity and gestational age, But there were significant differences between two groups regard to type of pervious birth method, satisfaction of previous birth method, delivery agent, and early onset of breast feeding in previous birth method. ${ }^{23}$ In a study the authors established that negative experiences of vaginal birth were associated with fear of future vaginal births. ${ }^{32}$ Similarly, a study in Sweden found that at least $10 \%$ of pregnant women suffer from fear of childbirth, and failure to treat this fear may have a negative impact on the subsequent birth. ${ }^{33}$ In agreement with our study, Chinese medical staff who had a caesarean section claimed that they were satisfied with their birth experience and advised that to other pregnant women and only a small portion with previous experience of vaginal delivery were satisfied with their birth method and would advised that to other pregnant women. ${ }^{34}$ Some studies showed that onset of breast feeding might be affected by post cesarean section pain and Swedish women had more lactation problems after a planned caesarean section than a vaginal delivery. ${ }^{35,36}$ Other study established that after a vaginal delivery, concentration in peaks of oxytocin in maternal serum are less frequent than an emergency caesarean section. ${ }^{37}$

Most women in vaginal delivery group received their information significantly from midwives, prenatal classes and their families. The previous birth experience between two groups was not significant. Most of women in both groups received their child bring information from relatives and also previous childbirth experience but was not statistically significant. In Salehian study source of taking information regard to birth methods was in $22.3 \%$, family and relative members; $20.3 \%$ media; $14.5 \%$ obstetricians; $13 \%$ health providers; $9.8 \%$ book; $3 \%$ general practitioner and or a combination of them 38 .

\section{CONCLUSION}

According to the findings of this study it appears that most of Socio-demographic and economic characteristics are contribute to birth method selection but reproductive factors are less related to this selection. Well-designed Studies in this area, particularly in our country is very few and further studies are recommended.

\section{ACKNOWLEDGMENTS}

This study was supported by Ahvaz Jundishapur University of Medical Sciences. The authors appreciate the Research Deputy vice-chancellor for research affairs of Ahvaz Jundishapur University of Medical Sciences as well as all health centers and hospitals' staffs to their cooperation during data collection.

Funding: No funding sources

Conflict of interest: None declared

Ethical approval: The study was approved by the Institutional Ethics Committee

\section{REFERENCES}

1. Walker JM. Exploring change through education: birthing options for women. International Journal of Childbirth Education. 2009;24(1):37.

2. National institutes of health consensus development conference on cesare childbirth, September 1980. Bethesda, Md: National Institutes of Health. NIH publication; 1981:82-2067.

3. Armson BA. Is planned cesarean childbirth a safe alternative? Canadian Medical Association Journal. 2007;176(4):475-6.

4. Menacker F, Hamilton BE. Statistics NCfH. Recent trends in cesarean delivery in the United States: US department of health and human services, centers for disease control and prevention. National Center for Health Statistics; 2010.

5. Sharifi RAD, Fathian Z, Tirani M, Mahaki B. Study on behavioral intention model (BIM) to the attitude of pregnant women toward normal delivery and cesarean section in province of Esfahan-Khomeiny shahr-1385. Journal of Ilam University of Medical Sciences. 2007;15(1):19-24.

6. Shahoei R, Riji HM, Saeedi ZA. 'Safe passage': pregnant Iranian Kurdish women's choice of childbirth method. Journal of advanced nursing. 2011;67(10):2130-8.

7. Yazdizadeh B, Nedjat S, Mohammad K, Rashidian A, Changizi N, Majdzadeh R. Cesarean section rate in Iran, multidimensional approaches for behavioral 
change of providers: a qualitative study. BMC health services research. 2011;11(1):159.

8. Sharyat M, Majlessi FA, Mahmoudi M. The prevalence of cesarean delivery and related factors. Payesh. 2002;1:5-10.

9. Iran Ministry of Health and Medical Education (IMHME), Organization of Mother and Child Health, 2010. Available at (http://www.fhp.hbi/FHPPages/MothersOfficeHealth INDpage.htm)(Persian).

10. Jackson NV, Irvine LM. The influence of maternal request on the elective caesarean section rate. Journal of Obstetrics and Gynaecology. 1998;18(2):115-9.

11. Wiklund I, Edman G, Larsson C, Andolf E. Personality and mode of delivery. Acta obstetricia et gynecologica Scandinavica. 2006;85(10):1225-30.

12. McCourt C, Weaver J, Statham H, Beake S, Gamble J, Creedy DK. Elective cesarean section and decision making: a critical review of the literature. Birth: Issues in Perinatal Care. 2007;34(1):65-79.

13. Hildingsson I, Rådestad I, Rubertsson C, Waldenström U. Few women wish to be delivered by caesarean section. BJOG: an International Journal of Obstetrics and Gynaecology. 2002;109(6):618-23.

14. Joseph K, Young DC, Dodds L, O'Connell CM, Allen VM, Chandra S, et al. Changes in maternal characteristics and obstetric practice and recent increases in primary cesarean delivery. Obstetrics and Gynecology. 2003;102(4):791-800.

15. Waldenström U, Hildingsson I, Ryding EL. Antenatal fear of childbirth and its association with subsequent caesarean section and experience of childbirth. BJOG: An International Journal of Obstetrics and Gynaecology. 2006;113(6):638-46.

16. Gamble JA, Creedy DK. Women's preference for a Cesarean section: incidence and associated factors. Birth: Issues in Perinatal Care. 2001;28(2):101-10.

17. Fenwick J, Hauck Y, Downie J, Butt J. The childbirth expectations of a self-selected cohort of Western Australian women. Midwifery. 2005;21(1):23-35.

18. Fenwick J, Gamble J, Hauck Y. Believing in birth choosing VBAC: the childbirth expectations of a self-selected cohort of Australian women. Journal of Clinical Nursing. 2007;16(8):1561-70.

19. Gamble JA, Creedy DK. Women's request for a cesarean section: a critique of the literature including commentary by DeMott RK. Birth: Issues in Perinatal Care. 2000;27(4):256-65.

20. Mancuso A, De Vivo A, Fanara G, Settineri S, Triolo $\mathrm{O}$, Giacobbe A. Women's preference on mode of delivery in Southern Italy. Acta obstetricia et gynecologica Scandinavica. 2006;85(6):694-9.

21. World Health Organization. www.who.int/reproductive-health Research, 2009.

22. Vafaee R, Hosseini F, Dashdebi KG, Momen bellah fard MJ, Ghalandari M, Gharlipour Z, et al. Assessing the factors influencing delivery method selection in pregnant women referred to Public hospitals in Shirazr. Journal of Nursing and Midwifery. 2013;81(23):13-8.

23. Nourizadeh R, Mohamadpoor A, Kazempoor RM, Aghdam FB. Assessing birth method selection and related factors in women in Marand, Iran. Urumieh Journal of Nursing and Midwifery. 2010;7(1):50-7.

24. Johnston T, Coory M. Increase in caesarean section rates among low-risk women in Queensland, 19902004. Medical Journal of Australia. 2006;185:404-5.

25. Laws P, Sullivan EA. Australia's mothers and babies 2003. National Perinatal Statistics Unit, Australian Institute of Health and Welfare: Sydney; 2005:82.

26. Roberts C, Tracy S, Peat B. Rates for obstetric intervention among private and public patients in Australia: population based descriptive study. British Medical Journal. 2000;321:137-41.

27. Murray SF. Relation between private health insurance and high rates of caesarean section in Chile: qualitative and quantitative study. BMJ. 2000;321(7275):1501-5.

28. Lauer JA, Betrán AP, Merialdi M, Wojdyla D. Determinants of caesarean section rates in developed countries: supply, demand and opportunities for control. World Health Report Background Paper. 2010:29.

29. Souza JP, Gülmezoglu A, Lumbiganon P, Laopaiboon M, Carroli G, Fawole B, et al. Caesarean section without medical indications is associated with an increased risk of adverse short-term maternal outcomes: the 2004-2008 WHO Global Survey on Maternal and Perinatal Health. BMC Medicine. 2010;8(1):1

30. Béhague DP, Victora CG, Barros FC. Consumer demand for caesarean sections in Brazil: informed decision making, patient choice, or social inequality? A population based birth cohort study linking ethnographic and epidemiological methods. BMJ. 2002;324(7343):942.

31. Abbaspoor Z, Moghaddam-Banaem L, Ahmadi F, Kazemnejad A. Iranian mothers' selection of a birth method in the context of perceived norms: A content analysis study. Midwifery. 2014;30(7):804-9.

32. Fisher C, Hauck Y, Fenwick J. How social context impacts on women's fears of childbirth: A Western Australian example. Social Science and Medicine. 2006;63(1):64-75.

33. Waldenström U, Hildingsson I, Ryding EL. Antenatal fear of childbirth and its association with subsequent caesarean section and experience of childbirth. BJOG: An International Journal of Obstetrics and Gynaecology. 2006;113(6):638-46.

34. Ouyang YQ, Zhang Q. A study on personal mode of delivery among Chinese obstetrician-gynecologists, midwives and nurses. Archives of gynecology and obstetrics. 2013;287(1):37-41.

35. Karlström A, Engström-Olofsson R, Nystedt A, Sjöling M, Hildingsson I. Women's postoperative experiences before and after the introduction of spinal opioids in anaesthesia for caesarean section. Journal of clinical nursing. 2010;19(9-10):1326-34. 
36. Carlander AKK, Edman G, Christensson K, Andolf E, Wiklund I. Contact between mother, child and partner and attitudes towards breastfeeding in relation to mode of delivery. Sexual and Reproductive Healthcare. 2010;1(1):27-34.

37. Nissen E, Uvnäs-Moberg K, Svensson K, Stock S, Widström AM, Winberg J. Different patterns of oxytocin, prolactin but not cortisol release during breastfeeding in women delivered by caesarean section or by the vaginal route. Early human development. 1996;45(1):103-18.

38. Salehian T, Delaram M, Safdari F, Jazayeri F. Knowledge and attitudes of pregnant women about mode of delivery in health centers of Shahrekord. Shahrekord Journal of Nursing and Midwifery, 2005;6(2):1-9.

Cite this article as: Abbaspoor Z, Noori MJ. The relationship of socio-demographic and reproductive factors with preferred type of birth. Int J Reprod Contracept Obstet Gynecol 2016;5:1765-72. 